\title{
EPISTEMOLOGIAS FEMINISTAS E CIÊNCIA DA INFORMAÇÃO: ESTUDOS E IMPLICAÇÕES
}

\author{
EPISTEMOLOGIES AND INFORMATION SCIENCE: \\ STUDIES AND IMPLICATIONS
}

\author{
Carlos Cândido de Almeida ${ }^{a}$ \\ Rosa San Segundo Manuelb
}

\begin{abstract}
RESUMO
Objetivo: Apresentar os estudos que revisam o tema e os que não revisam concretamente a questão do gênero e da mulher na ciência da informação, porém sustentando que apenas os estudos crítico-revisionistas-críticos teriam o compromisso de fazer avançar o debate no sentido de lançar questões epistemológico-feministas à área. Metodologia: Segue um procedimento bibliográfico seletivo, elencando trabalhos que ilustram vários temas relativos à mulher inseridos na ciência da informação. Resultados: Para incorporar elementos das epistemologias feministas à ciência da informação devem ser revistas a concepção de ciência da informação, a discussão de sua identidade, a incorporação da teoria de gênero, a integração dos esforços de renovação da linguagem, o questionamento do gênero nos métodos de pesquisa e a neutralidade das tecnologias da informação. Entre empirismo, ponto de vista feminista e feminismo pós-moderno na ciência, pode-se elencar pontos que implicam mudanças na ciência da informação. Conclusões: Os trabalhos crítico-revisionistas têm manifestado diversos problemas do uso da linguagem na reprodução dos preconceitos, mas sugere-se olhar para outras frentes de atuação da área em que se fazem necessária a incorporação mais aprofundada de uma abordagem feminista. $O$ pensamento patriarcal se esconde sob um verniz pluralista, mas segue as mesmas diretrizes de ciência-padrão e elege quem está autorizado a defini-la.
\end{abstract}

Descritores: Epistemologias Feministas. Ciência da Informação. Estudos Críticos.

\footnotetext{
a Doutor em Ciência da Informação pela Universidade Estadual Paulista (UNESP). Docente do Departamento de Ciência da Informação da Universidade Estadual Paulista. (UNESP). E-mail: carlos.c.almeida@unesp.br

b Doctora en Biblioteconomía y Documentación pela Universidad Complutense de Madrid (UCM). Docente Profesora de lo Departamento de Biblioteconomía y Documentación de la Universidad Carlos III de Madrid (UC3M). Diretora do Instituto de Estudios de Género. E-mail: rsan@bib.uc3m.es.
} 
"A partir de mediados de los años setenta, las críticas feministas de la ciencia han evolucionado desde una postura reformista

a otra revolucionaria, de unos análisis que daban la posibilidad de mejorar la ciencia que tenemos a la reivindicación de una transformación de los mismos fundamentos de la ciencia y de las culturas que le otorgan su valor."

(Sandra Harding, 2016, p. 11)

\section{INTRODUÇÃO}

É notório que nos últimos anos a ciência da informação tem incorporado perspectivas feministas em seus estudos, mas argumenta-se que isso tem ocorrido ainda em um nível inicial. Em muitos casos, o feminismo, ou mais apropriadamente o tema mulher, é tratado apenas como uma variável que ainda não sustenta uma discussão a respeito da reforma das diretrizes da ciência da informação.

Pode-se classificar arbitrariamente esses estudos desenvolvidos no interior da ciência da informação como: estudos gerais e estudos críticorevisionistas. Os estudos gerais e não revisionistas têm o compromisso de produzir apenas índices que representam um diagnóstico sobre a distribuição de um assunto em um dado grupo de publicações ou comunidade científica. Entende-se por revisão uma postura mais abrangente que a simples indicação da situação de um tema em um corpus da literatura. O segundo grupo, críticorevisionistas, vai um pouco mais longe e busca rever algum tópico ou pinçar amostras do universo de práticas, processos e instrumentos da ciência da informação como modelares do tratamento dispendido à mulher.

Não obstante, uma revisão do ordenamento da ciência da informação sob princípios das epistemologias feministas, isto é, seguindo as consequências lógicas possíveis da aplicação do debate presente em estudo anterior, somente será possível com a discussão da concepção da ciência da informação.

Seguindo um procedimento bibliográfico bem seletivo, elencando trabalhos que ilustram vários temas relativos à mulher inseridos na ciência da informação, o objetivo deste artigo é referendar a importância desses estudos para o avanço do tema, porém sustentando que apenas os estudos revisionistas 
teriam o compromisso de fazer avançar a ciência da informação no sentido de lançar questões epistemológico-feministas à área.

Isso posto, passa-se a exemplificar esses trabalhos utilizando duas analogias aproximativas: a mulher-palavra, um tratamento indireto da questão produzido por estudos gerais e não revisionistas, e a mulher-objeto, momento em que a mulher deixa de ser apenas palavra ou tema e ganha o status de objeto de estudo em diversas áreas da ciência da informação. Após essa exposição, serão apresentadas algumas implicações epistemológico-feministas à ciência da informação.

\section{A MULHER-PALAVRA}

Em termos linguísticos, deve-se prestar atenção quando e como os signos são utilizados. Em muitos casos, a sobrevalorização do significante pode prejudicar o significado; isto é, a expressão pode roubar a cena principal representada pelo conteúdo. No caso dos interesses feministas da área, estudar apenas a palavra pode não contribuir para as mudanças práticas desejadas, embora signifique um tipo de compreensão da questão.

Os estudos que se voltam às palavras, não apenas à palavra mulher, mas gênero, relações de gênero etc., são fundamentais para a ciência da informação reconhecer o seu percurso histórico e como pesquisadoras e pesquisadores foram alterando a sua postura frente a determinados assuntos. Contudo, o carácter de diagnóstico desses estudos não sugere concretamente uma revisão da postura da ciência. Por isso, entende-se que seriam contribuições gerais e não revisionistas porque não resultam necessariamente em uma proposta consistente de revisão da questão pois trata-se de um diagnóstico relativamente bem estruturado'.

Gênero e demais palavras-chave associadas à mulher foram

\footnotetext{
1 Um exemplo de contribuição concreta de natureza revisionista seria um estudo que vise a um plano de igualdade de gênero nos departamentos, programas de pós-graduação, bancas, coordenação de projetos de pesquisa, coordenação de revistas científicas, reformulação de instrumentos de representação etc. Revisionista aqui não pode ser confundido como o movimento de revisão história, embora o processo desconstrucionista estaria presente no cerne da abordagem.
} 
investigadas como assunto, assim como se tem feito com um sem-número de temas na ciência da informação. $O$ aspecto indiciário desses estudos importam para o reconhecimento do campo, mas nem sempre voltam-se a propostas de ação. É a presença das palavras na literatura o objeto como substituto do objeto ou dos fenômenos que interessa conhecer.

Com base nos comentários lançados em artigo anterior sobre as epistemologias feministas (empirismo, ponto de vista e pós-moderno), deve-se reconhecer a hipótese de que nem todo estudo sobre a mulher ou sobre gênero, é um estudo com perspectiva de gênero. Consequentemente, poder-se-ia admitir que não são todos os estudos sobre a mulher-palavra que promovem o movimento feminista ou especificamente, a incorporação de epistemologia feminista.

O interesse pela comunidade brasileira da área sobre o tema remonta os anos 1990. A produção nesse sentido vem crescendo vertiginosamente. Santo (2008, p. 321) realizou um levantamento em publicações nacionais e internacionais, bem como em evento nacional da área de ciência de informação no período de 2000 a 2007 e que relacionaram o tema mulher e informação.

A autora identificou 18 artigos internacionais, 6 nacionais e 4 trabalhos no Enancib, chegando a seguinte conclusão:

Detectamos como ponto comum entre os artigos analisados, tanto nacionais quanto internacionais, ser necessário que as ciências, de uma maneira geral, invistam em estudos que possam detectar as desigualdades de gênero, buscando alternativas para modificar esse quadro. (SANTO, 2008, p. 327).

Embora se recomende o aprofundamento na temática não está claro que o aumento quantitativo de trabalhos redundará em maior consciência feminista e diminuição da desigualdade de gênero, pois dependerá do tipo de estudo. Entende-se que a estratégia não é apenas quantitativa, tal como preconizado pelo empirismo feminista, mas deveria ser qualitativa, de modo a repensar as formas de se investigar.

Na mesma linha, Bufrem e Nascimento (2012) realizaram um estudo com o objetivo de identificar a presença do gênero com base na presença da mulher como produtora de conhecimento e analisar a temática gênero na literatura da ciência da informação no Brasil. Para tanto, utilizaram como descritores os 
termos "gênero" e "mulher" para recuperar artigos científicos na Base de Dados Referencial de Artigos de Periódicos em Ciência da Informação (BRAPCl), de 1972 a 2011. A tese investigada foi a suposição de que a ciência da informação baseia-se na neutralidade e é apática quanto aos temas políticos e sociais. Em termos metodológicos, Bufrem e Nascimento (2012, p. 204), fundamentadas em Solla Price, recorreram aos métodos bibliométricos para entender a distribuição da quantidade de autores, trabalhos, países e revistas.

Como resultado, Bufrem e Nascimento (2012, p. 205) encontraram 74 artigos de 102 autores diferentes no período investigado, sendo que apenas 18 $(16,22 \%)$ produziram mais de um trabalho. Contudo, relataram que o índice de transitoriedade é elevado, com $83,78 \%$, além disso, do total de 102 autores, $79,28 \%$ são mulheres, o que deixa claro a responsabilidade das mulheres em produzir sobre o assunto. Outros dados também foram relevantes na análise das autoras: a) 74 (63,41\%) artigos analisados foram escritos por um único autor; b) $58,56 \%$ dos autores são doutores; c) $63,96 \%$ dos autores dedicam-se à docência; d) há baixo índice de autoria na categoria pós-graduação; e) 18,02\% de autores representa um núcleo proveniente do sul do Brasil; f) $8,12 \%$ da produção vincula-se a FURG, seguida das universidades PUCCAMP, UFRGS, UFSCAR, UNB, UNIVALI, estrangeiras e outras; g) as áreas de formação mais representativas são biblioteconomia, ciência da informação, comunicação, educação, psicologia, sociologia, entre outras; h) houve dois momentos importantes nessa produção, de 1972 a 1986, em que o tema foi pouco abordado e de 1987 a 2001, com 25 trabalhos sobre o assunto.

De maneira geral, a análise da situação do tratamento do tema pela ciência da informação no Brasil pode parecer mais voltado ao estudo das palavras em uma literatura, contudo, é o tipo de crítica que se realiza que permite classificar um estudo como mais ou menos propositivo para uma discussão da ciência. Nesse sentido, essa primeira parte da descrição dos dados de Bufrem e Nascimento (2012) é similar aos outros estudos da mesma categoria, não obstante, as críticas feitas propõem uma reflexão mais ampla sobre a ciência, como se verá na próxima seção.

Lima e Dias (2013, p. 4) buscaram contribuir com a articulação da ciência 
da informação com os estudos de gênero investigando as pesquisas sobre mulher e relação de gênero em periódicos da área presentes na Base de Dados Referencial de Artigos de Periódicos em Ciência da Informação (BRAPCI). Para tanto, fizeram um levantamento no período de 1972 a 2011 com base na presença das palavras nos títulos e no campo palavras-chave (mulher/es e relações/estudos de gênero). As autoras não localizaram artigos no período de 1970-1989, diferentemente da década seguinte 1990-1999 quando recuperaram 18 artigos (LIMA; DIAS, 2013, p. 6). No intervalo compreendido pela década de 2000-2009, localizaram 41 trabalhos e no período de 2010-2011, foram 12 artigos. Contudo, do total de 71 trabalhos, identificaram 15 repetições entre palavras-chave e título.

De certa forma, o estudo reforça os resultados de Santo (2008) e atesta ser um fenômeno recente tratar do tema na ciência da informação brasileira. Segundo Lima e Dias (2013, p. 14), "Apesar de existirem muitos trabalhos sobre gênero oriundos de diversas partes do mundo, poucas referências são feitas às questões concernentes a gênero e informação."

Com a mesma atenção às palavras, Siciliano, Souza e Meth (2017) continuaram com a preocupação de produzir um diagrama da situação na ciência da informação. As autoras relacionaram os "tópicos" mais indicados pela ciência da informação no domínio gênero. Nesse caso, questiona-se aqui sobre a possibilidade de refletir com profundidade sobre um domínio com base em índices tão gerais sobre uma área. Conforme defendem as autoras: "É necessário, portanto, refletir sobre o domínio 'gênero' na $\mathrm{Cl}$, no âmbito da organização do conhecimento, com fins de identificar como o campo se apropria e/ou contribui para os estudos relacionados a gênero." (SICILIANO; SOUZA; METH, 2017, p. 145).

Os resultados da pesquisa não permitiram alcançar essa reflexão, menos ainda no âmbito da organização do conhecimento. O que foi produzido foi um agrupamento de palavras-chave, contabilizadas junto aos artigos na base Library \& Information Science Abstracts (LISA) no campo assunto principal e a forma de apresentação foi um diagrama de nuvem. $O$ aspecto indiciário dos resultados desse último estudo não garante ou fomenta a ansiada reflexão e a esperada 
mudança nas práticas de discriminação.

Siciliano, Souza e Meth (2017) reconheceram o papel desempenhado pelas autoras Santo (2008) e Lima e Dias (2013), mas destacando que elas trabalharam com a produção científica brasileira, diferentemente do que propuseram. Os artigos apareceram entre o período que vai de 1980 a 2016 , com a recuperação de 588 artigos, ressaltando que não foram encontrados artigos com a palavra-chave gender antes da década de 1980 (SICILIANO; SOUZA; METH, 2017, p. 148).

As autoras separaram a quantidade de artigos por data de publicação e os agruparam por décadas. Siciliano, Souza e Meth (2017) sistematizaram os resultados e apontaram que a década de 1980 registrou 4 artigos (com destaque para os termos library staff, job performance, efficiency e evaluation), na década de 1990 registraram 78 artigos (com destaque para as palavras gender - 59x, information - 12x, communication - 11x, women - 11x, e world wide web-10x), na década de 2000 recuperaram 229 artigos (destacando as palavras gender 117x, gender differences - 51x, women-29x, information technology - 28x e users - 27x) e na década de 2010 foram recuperados 277 artigos (destacam-se as palavras gender - 145x, gender differences - 55x, women - 34x, social networks - 29x e scholarly publishing -23x). Como o estudo foi realizado no ano de 2017, a última década avaliada compreendeu os anos de 2010 a 2016 apenas.

O trabalho de Matos e Oliveira (2017) foi ainda mais modesto em termos de abrangência. As autoras procuraram identificar as tendências de assuntos e as características de autoria presentes no periódico brasileiro Revista de Estudos Feministas. Para identificação dos temas foi utilizado o Tesauro para Estudo de Gênero e sobre Mulheres da Fundação Carlos Chagas. O levantamento compreendeu o período de 2001 a 2016, tendo resultado em um corpus de 298 artigos e identificado 421 autores. Desse grupo, 28 autores voltaram a publicar no periódico ou menos de $7 \%$ do total e responsável por $25 \%$ do total de artigos selecionados. Em síntese, como resumido pelas autoras,

Houve uma maior quantidade de publicações relacionadas às discussões teóricas, através de estudos de epistemologias feministas, parentalidade, questões de sexualidade, papéis de gênero na sociedade e as relações de gênero, raça e classe. (MATOS; OLIVEIRA, 2017, p. 8). 
Esse último artigo é uma variação dos anteriores. A relação com a ciência da informação não é explorada, mas utilizam-se de técnicas presentes na área como forma de conhecer o "comportamento" das palavras associadas aos estudos da mulher, de gênero e do próprio feminismo. Esse procedimento pode ser aplicada a uma revista ou a um corpus mais ou menos coerente, porém, dependendo do tipo de análise que se realize, o que se obterá é uma lista, com forma de diagrama ou não, de temas ou autores. Contudo, o peso da análise do significante - a centralidade do plano de expressão de termos em um espaço diagramado - supera a interpretação do significado. Em termos lógicos, a intensão de uma palavra não substitui a sua compreensão nem a extensão, assim como o significante não substitui o significado ou o referente.

Pinho e Milani (2020), por sua vez, discutiram os aspectos éticos da organização do conhecimento no que tange os termos considerados fronteiriços com respeito a gênero e sexualidade. Os autores objetivaram categorizar esses termos com o objetivo de formar uma base léxica (PINHO; MILANI, 2020, p. 88). Reconheceram que a produção científica do tema ainda sofre com falta de representação e que não há um vocabulário controlado e normalização dos vocábulos desse domínio. Isso, obviamente, prejudica a recuperação da informação de maneira precisa.

O estudo pode ser considerado terminológico e coincide com o tratamento da palavra, embora enfatize a significação, pois a ênfase recai sobre um corpus formado por termos fronteiriços identificados em artigos das revistas Journal of Homosexuality, Sexualities e Journal of Gay \& Lesbian Mental Health, no período de 2010 a 2019 (PINHO; MILANI, 2020, p. 94). O levantamento sistematizou uma base com 1.962 termos com incidência igual ou superior a 10 vezes, e após uma seleção chegaram a 12 termos metafóricos e 35 termos fronteiriços ${ }^{2}$. A análise dos termos entre gênero e sexualidade tem como fonte a literatura científica e

\footnotetext{
2 Segundo Pinho e Milani (2020, p. 94), foram encontrados os seguintes termos: "agender, aliagender, ambigender, androgine, bigender, (female-male), butch non-binary, cristaline, demigender, denboy, demigirl, efemere, femme non-binary, genderfluid (female-male), genderflux, genderfuck, genderpivot, genderqueer non-binary, graygender, malenon-binary, intergender ou intersex, female non-binary, nan0gender, nan0boy, nan0girl, nan0-menine, negative, neutrois, pangender, poligender, positive, third gender, transfemale ou male to female, transmale ou female to male, travestite non-binary e trigender."
} 
não foi objetivo conhecer a questão fora do âmbito da palavra.

Após a identificação dos termos, os autores categorizaram-nos com base nas facetas de Ranganathan (Personalidade - P, Matéria - M, Energia - E, Espaço - S, Tempo - T, PMEST) e produziram um quadro explicativo bem sugestivo sobre essas definições, o que já se constitui um tipo de controle terminológico. O intento foi pensar em uma estratégia de controle terminológico para termos de fronteira. Contudo, considera-se que a explicação sobre o que é termo de fronteira poderia ser melhor elucidada dada a centralidade que ocupa na discussão.

Pinho e Milani (2020, p. 100), concluem o estudo afirmando que os temas gênero e sexualidade têm recebido maior atenção dos pesquisadores, contudo, tal produção carece de representação documentária adequada, bem como normalização terminológica que favoreça a indexação de documentos. Nesse sentido, a ausência desses produtos prejudica a recuperação da informação. Assim, entende-se aqui que o componente ético da discussão seria justamente deixar de representar de maneira adequada essa literatura.

Como visto, a questão de Pinho e Milani (2020) é terminológica. O interesse é tratar do gênero, o que incluir a significação do termo mulher no contexto de uma teoria mais ampla, e não apenas feminista. Não obstante, o debate ainda fica reduzido às tentativas de melhor representar como um tipo de esforço ético para construir novos sistemas adaptados a certos públicos. A questão dos instrumentos, se a sua estrutura é adequada ou não a um paradigma científico, não foi o objetivo de investigação.

Encerra-se esta discussão com o trabalho de Vasconcelos e Farias (2020), que atesta os estudos que buscam discutir autoria feminina na área de ciência da informação, valem-se de métodos bibliométricos. Em outros termos, a mulher é vista como palavra. O problema das autoras era saber como os estudos de autoria feminina estão sendo desenvolvidas na área. Para tanto, objetivaram apresentar um panorama da produção científica abordada na ciência da informação. A base teórica da discussão foi o reconhecimento da ciência e da tecnologia como ambientes masculinos, o qual deve ter suas bases questionadas. Argumentam Vasconcelos e Farias (2020, p. 8) que "A 
neutralidade da ciência é colocada em xeque pelo enfoque do gênero [...]", assim, de certa forma, reporta-se a uma discussão mais ampla da epistemologia feminista, embora não tenha sido avançada no estudo.

Por sua vez, como método, as autoras buscaram identificar na base BRAPCI, no período de 1972 a 2019, os termos estudos de gênero, produção científica e feminina e produção feminina; precisamente nos campos título, palavras-chave e resumo. Após o levantamento, identificaram 128 artigos em uma primeira seleção que, depois da análise dos resumos, terminaram por selecionar apenas 13 artigos (VASCONCELOS; FARIAS, 2020, p. 10).

Entre os resultados, Vasconcelos e Farias (2020) destacam que: a produção científica manteve-se estável entre os anos 2007, 2008, 2011, 2013, 2016 e 2018, mas com elevações nos anos 2012, 2017 e 2019; as produções sobre $o$ assunto são de autoria de mulheres em sua maioria, mostrando que elas estão mais preocupadas em abordar o assunto na ciência; as palavras-chave encontradas reportam-se a um número específico de termos, com ênfase para o termo gênero (frequência absoluta: 14), além dos termos produção científica (5), mulheres (5), ciência da informação (4), indicadores de C\&T (3), estudos métricos (3), estado da arte (2) e periódico científico (2). Ademais, segundo Vasconcelos e Farias (2020, p. 18), o aspecto mais importante é a natureza dos estudos:

Observa-se que a escolha por estudo bibliométrico é uma característica que sobressai no corpus. [A] justificativa pode ser pelo fato desse ser tradicionalmente um dos métodos mais utilizados na Ciência da Informação e em outros campos de conhecimento para entender a produção científica.

Nesse sentido, Vasconcelos e Farias (2020) demonstram que os estudos de tratam da autoria utilizam a abordagem bibliométrica que, tal como comentado, centra-se na palavra e em suas relações com temas, instituições e períodos.

A respeito dessa categoria geral de contribuições é possível inferir duas coisas óbvias: que houve um incremento de publicações ao passar dos anos e que os temas de estudo foram mudando. Contudo, esse tipo de conclusão que se produz não alcança com profundidade o teor dos problemas enfrentados pelo feminismo epistemológico. Com trabalhos centrados na palavra não chega a 
saber o significado das coisas. Por exemplo: quais os problemas enfrentados pelas mulheres no ambiente de trabalho? quais as barreiras para o acesso aos postos mais elevados na burocracia científica? quais são as limitações nos sistemas de retribuição e reconhecimento das pesquisadoras? que métodos podem ocultar ou enfatizar variáveis de gênero etc.? A estrutura dos instrumentos de organização do conhecimento não é avaliada, tampouco as relações entre a linguagem e a reprodução do poder nos sistemas sociais.

Em síntese, essas são as características dos estudos entendidos aqui como gerais e de conteúdo não plenamente revisionistas, pois a análise da mulher-palavra, embora útil, é limitada para a construção de uma perspectiva epistemológica feminista na ciência da informação.

\section{A MULHER-OBJETO}

Outros estudos têm abordado a questão da mulher de uma forma um pouco mais profunda. A mulher não é um assunto de uma literatura ou conjunto de revistas apenas, mas um objeto que se constata na prática. Nesse sentido, deve-se relacionar alguns trabalhos que se entende como crítico-revisionistas por discutirem a necessidade de revisão da situação da mulher nos campos social, ocupacional, científico e de instrumentos de organização.

Ferreira (2003) procurou refletir sobre o problema da profissão bibliotecária em um contexto de feminização. A autora tratou dos estudos de gênero no Brasil e a condição da mulher no mundo do trabalho. Ferreira (2003, p. 193) assume que pesquisar mulher e gênero na biblioteconomia é sempre difícil porque os profissionais não relacionam a desvalorização com a característica feminina da categoria. Segundo a sua reflexão, por uma questão cultural, as mulheres tendem a escolher profissões de serviço, de cuidados, as quais são menos competitivas, com pouco retorno econômico e prestígio reduzido. Fazem isso não por falta de competência ou conhecimentos, mas por uma visão de mundo a elas inculcada a respeito do que deve ser uma mulher.

Amparada em teses marxistas, a autora entende que "Por meio dos estudos de gênero é possível compreender como se dão os processos que têm, historicamente, submetido a mulher às posições de inferioridade." (FERREIRA, 
2003, p. 197). E, para avançar nessa interpretação, Ferreira (2003, p. 198) sugere como caminho construir uma nova identidade da área, com uma práxis que transforme a realidade, a partir da revisão de currículos, articular ação pedagógica com ação política e assim combater a ignorância e a alienação sobre a questão.

A autora considera a mulher e a profissão bibliotecária como objeto de reflexão. Parte de premissas da realidade social, como a tendência das profissões de serviço e de cuidados estarem associadas às mulheres. Nesse sentido, o trabalho pode ser classificado dentro do grupo crítico-revisionista que entende os problemas da mulher e busca soluções teóricas para a ação. Há uma nítida diferença entre esta abordagem e o simples diagnóstico das publicações sobre o tema, tal como na ênfase da mulher-palavra.

Como verificado, Bufrem e Nascimento (2012), além de descreverem amplamente a situação do tema gênero na literatura, contribuindo ao estudo da situação de uma palavra em um corpus, também acrescentaram à reflexão alguns pontos que merecem destaque: 0 aumento das publicações demonstram o avanço do debate, contudo a grande maioria dos autores são mulheres, o que, no caso, pode ser explicado pela ligação que as autoras têm com a formação em biblioteconomia, tal como caracterizado por Ferreira (2003).

Considerando que a ciência possui um carácter social e que outros métodos devem ser empregados para estimular o estudo, pois se trata, ao fim e ao cabo, da análise das relações de poder, Bufrem e Nascimento (2012, p. 212) concluem que a ascensão da mulher no círculo acadêmico-científico ainda é ainda hostil, e a escolha por uma profissão descende de práticas institucionalizadas, sendo assim, deve-se estabelecer políticas afirmativas para incentivar a participação feminina na ciência.

Não obstante, no campo ocupacional, a situação também não é menos hostil. Muller e Martins (2019) mostraram que as mulheres bibliotecárias no Brasil ultrapassam $80 \%$, contudo, representam $50 \%$ na presidência dos conselhos regionais da área. A questão central é que os cargos de chefia ou de representação política são ocupados em uma proporção muito diferente do quantitativo de profissionais. Contraditoriamente, a biblioteconomia é 
amplamente conhecida como profissão generizada, mas são os homens que ocupam os mais altos postos de decisão.

Contudo, a principal linha de discussão aqui ou mesmo de aplicação dos pressupostos feministas, está constituída pelo estudo da linguagem. $O$ pressuposto geral é que a linguagem não é transparente nem neutra e, no caso, encerra um ordenamento do mundo perspectivado e centralizado pelo universo masculino. O uso da linguagem para organizar a realidade social no âmbito da ciência da informação pode ser vislumbrado nos termos de indexação, catálogos de assuntos, nas classes e categorias presentes nos sistemas de organização do conhecimento.

A intenção é apresentar amostras da situação da mulher recorrendo a terminologia utilizada e defendendo que há uma relação causal entre a representação produzida pelos instrumentos utilizados pelos profissionais da informação e a assimilação cognitiva de categorias androcêntricas. Essa assimilação impactaria os profissionais, mas também a própria sociedade.

A relação mais consistente das epistemologias feministas com a ciência da informação, deu-se em estudos crítico-revisionistas que discutem principalmente os instrumentos de organização do conhecimento, seus vieses e preconceitos. Entre os instrumentos destacam-se a Classificação Decimal de Dewey, a Classificação Decimal Universal, os tesauros e os cabeçalhos de assunto.

Tal como foi comentado, a discussão do feminismo na ciência da informação se acentua nos anos 1990. Contudo, considera-se aqui como a primeira grande contribuição para a discussão do assunto o trabalho de Fox e Olson (2012). Qualifica-se desse modo pela capacidade das autoras de sistematizarem as principais correntes epistemológicas e teóricas afeitas ao feminismo. As autoras revisaram a relação sujeito-objeto, trataram do empirismo feminista, apontaram os tipos de epistemologia social em que se inserem as linhas epistemológicas feministas, tais como: a teoria do ponto de vista femininista, o conhecimento situado, bem como a relação da epistemologia social com a organização da informação. Sobretudo, indicaram as tendências mais conhecidas como epistemologia pós-estrutural e o pós-colonialismo 
feminista. Além das reflexões endereçadas aos instrumentos, Fox e Olson (2012) indicaram as questões candentes da organização do conhecimento por linha epistemológica, as quais se sistematizou da seguinte forma:

- "Questões do empirismo feminista: Grupos marginalizados como as mulheres são representados nos sistemas de organização do conhecimento da mesma forma que os grupos estabelecidos? Há preponderância de mulheres nas atividades de catalogação e indexação relativo ao que ocorre com o resto da ciência da informação? Quais variáveis estão relacionadas com a diversidade de áreas de atuação, como salário, grau de autonomia, número de oportunidades, motivação?

- Questões do ponto de vista feminista: Por que os homens são considerados a norma enquanto as mulheres estão nas margens do sistema e necessitam ser interpretadas pelo grupo estabelecido? Será que catalogadoras e indexadoras estão felizes com o seu trabalho? Estas profissionais estão satisfeitas, frustradas ou resignadas?

- Questões do pós-estruturalismo feminista: Os discursos regem as escolhas atrás dessa situação? Quais discursos governam este fenômeno de associar as mulheres com os serviços de secretariado ou escritório? Por que essas atividades são pesadas e regidas por padrões justamente desenvolvidos por outros sujeitos?

- Questões à organização do conhecimento: Como são as representações da mulher, das mulheres e de outros sexos, gênero e tópicos culturais e biológicos nos sistemas de organização? Por que as profissionais catalogadoras e indexadoras não são posições consideradas prestigiadas como as outras do campo da ciência da informação?" (FOX; OLSON, 2012, p. 95, tradução nossa).

Com efeito, as autoras cobrem as principais questões decorrentes da aplicação das linhas epistemológicas feministas no campo da organização do conhecimento. Fox e Olson (2012) avançam na linha estabelecida por Ferreira 
(2003) no sentido de compreender as razões do problema da profissão, em especial, na especialidade das indexadoras e catalogadoras.

Tratando especificamente dos instrumentos, como forma de demonstrar a objetivação do problema, cita-se o caso de uma análise sob a perspectiva de gênero e a discriminação de minorias na Classificação Decimal Universal, realizada por Mondéjar Madina, Marín García, e Santos Serra (1997). É importante sublinhar que o mesmo procedimento de revisão foi realizado pelas autoras com outras minorias políticas, fato que também é comum às pesquisas da ciência da informação.

É evidente que a linguagem exerce um papel hegemônico na sustentação de uma dada visão de mundo, e as representações em disputa requerem privilégios sobre o uso de expressões para moldar uma perspectiva da realidade. Contudo, a luta pelo domínio da linguagem não pode ser a meta final das investidas feministas. A busca por uma linguagem mais adequada nesta arena deve ser vista como a meta intermediária, pois o reordenamento epistemológico feminista seria o fim almejado. Não se nega a importante relação entre representação simbólica e epistemologia, apenas alude-se ao fato de que é necessário conscientizar-se sobre a questão que deve importar às pesquisadoras feministas da área passa primeiro pelas categorias epistemológicas: verdade, objetividade, cientificidade, método etc.

Nessa busca, o uso do masculino genérico é atacado em várias frentes. Mesmo as justificativas linguísticas que retomam a chamada economia da linguagem como um princípio simplificador, não são consideradas legítimas, pois sucumbe as mulheres à invisibilidade. Essa acertada crítica politicamente correta deixa claro que a linguagem tem meios para designar adequadamente as pessoas e os ajustes são possíveis de forma a representar mais apropriadamente a realidade e as evoluções sociais decorrentes. É mais uma questão de vontade política, e menos de limitações das formas linguísticas disponíveis.

No caso estrito da Classificação Decimal Universal, e que se pode aplicar a outros instrumentos, Morán Suárez e Rodríguez Bravo (2001, p. 3, tradução nossa) comentam que "Percebemos que a presença do feminino nesta 
classificação é escassa, inapropriada e assimétrica. Nomeia-se pouco as mulheres e, quando é feito, são associadas a escassas parcelas da realidade."

Olson (2003), por sua vez, tem oferecido uma grande contribuição ao tema. A autora foi um pouco mais adiante e propôs a necessidade de procedimentos de desconstrução pós-coloniais como meios para revisar as oposições binárias impostas aos conceitos. Por exemplo, há uma série de oposições binárias que adornam os conceitos, muitas das quais se utiliza para organizar o conhecimento, a saber: unidade-diversidade, identidade-diferença, centro-periferia, macho-fêmea, universalidade-diversidade. Sugere a autora que devemos analisar nossos sistemas Classificação Decimal de Dewey, Online Computer Library Center, Classificação Decimal Universal e entender que "O mais importante trabalho de desconstrução é revelar a especificidade de nossa 'universalidade'."(OLSON, 2003, p. 739, tradução nossa).

Olson ataca o problema da formação do conceito que servirá de base para a representação da informação. Esses conceitos devem ser revistos como base na desconstrução de modo a identificar as oposições binárias que em geral deixam a mulher em condição subalterna.

Para evitar esses vieses, é necessário incluir as responsabilidades dos profissionais. Segundo Alfaya Lamas (2011, p. 261), os profissionais devem reivindicar a sua responsabilidade e colaborar para a crítica e produção de sistemas de organização do conhecimento mais igualitários. Os efeitos do uso de termos não apropriados não estão apenas circunscritos aos sistemas de organização, estes representam um índice do que ocorre em outras frentes que buscam a representação das mulheres.

Em um caso particular mencionado por Fioravanti, Nascimento e Sabbag (2020, p. 490-491), a classificação existente em algumas instituições influencia a determinação da realidade representada, pois no caso da categoria de crimes que resultam em morte da mulher, estes foram classificados como homicídio qualificado e não como feminicídio. Assim, não se conhece a verdade dos fatos simplesmente pelo uso inadequado de representações que somente com a perspectiva de gênero tem sido revelado.

Retoma-se novamente as contribuições de Pinho e Milani (2020) que não 
somente fizeram um estudo terminológico, mas deixaram pistas de como construir uma proposta feminista mais potente à organização do conhecimento. Em primeiro lugar, os autores assumiram, à moda de Hope Olson, uma postura pós-estruturalista subjetivo. Entendem por isso, como bem explicam MartínezÁvila e Beak (2016, p. 360 apud PINHO; MILANI, 2020, p. 93), uma premissa ontológica que "[...] consiste na existência de múltiplas realidades e 0 posicionamento epistemológico tenta revelar as premissas subjacentes a essas realidades."

Em segundo lugar, e fundamentando-se em Fox e Reece (2012 apud PINHO; MILANI, 2020), listam os modelos epistemológicos que sustentam decisões éticas no campo ocupacional da biblioteconomia: modelo utilitarista ("somente as consequências importam ao determinar o valor moral de uma ação, e o bem comum do coletivo é o foco"); modelo de Rawls ou modelo da justiça ética; modelo deontológico de Kant que supõe que se considere mais do que as consequências para pensar se uma ação é correta; a ética de Derrida que defende a possibilidade da diferença em um sistema; a ética pragmática de John Dewey, isto é, "várias ações e consequências e todas as possibilidades lógicas que pertencem ao contexto da ação devem ser consideradas, testando-as com o auxílio de uma comunidade definida levando em conta sua vida moral" (FOX; REECE, 2012 apud PINHO; MILANI, 2020, p. 92-93). Por último, e não menos importante, consta a ética feminista:

Ética feminista - ética do cuidado: ética do cuidado não implica
afeto, mas uma estratégia que visa incluir colaboração,
relacionamentos e contexto ao processo de tomada de decisão
ética analisando os dilemas em seus contextos específicos e
acomodando as exceções. Na organização do conhecimento,
considerar ou conhecer todos os aspectos de um indivíduo em
particular que poderia realizar uma busca por assunto é inviável,
mas as pesquisas vêm buscando maneiras criativas de
acomodar o contexto dos usuários mantendo o controle
bibliográfico necessário; esse parece ser o paradigma atual da
organização do conhecimento. (FOX; REECE, 2012 apud
PINHO; MILANI, 2020, p. 92).

Esse último modelo epistemológico que sustenta as decisões éticas de bibliotecários poderia estender-se a toda a ciência da informação. Embora não tenha sido o objetivo central da análise de Pinho e Milani (2020), o fato de 
registrarem a epistemologia feminista como o paradigma atual da organização do conhecimento, através do trabalho de Fox e Reece, mostra que se está avançando a uma maior conscientização dos caminhos que deve seguir a ciência da informação.

Saindo do campo da organização do conhecimento, notam-se contribuições que passam pela reflexão sobre as formas de disseminação e comunicação de grupos de mulheres. Mais uma vez, as mulheres são apresentadas em um contexto e em uma dinâmica social. Assim como o exame dos instrumentos de organização do conhecimento e representação da informação desvelou as condições reais de representação das mulheres e como a linguagem - significado e significante - são utilizados para ocultar (FIORAVANTI; NASCIMENTO; SABBAG, 2020) ou subrepresentar a realidade (RODRÍGUEZ BRAVO; MORÁN SUÁREZ, 2001), a análise do acesso à informação avança na interpretação das mulheres reais como objeto de estudo.

Woida (2020) estudou o ciberfeminismo como fonte de informação de coletivos de mulheres. Essa mobilização efetivada no ambiente das redes foi tomado como movimento e prática social. Os coletivos designados como ciberfeministas atuam como verdadeiras fontes de informação, sugerem bibliografias, publicações, produzem conteúdo e atuam como espaço de encontro e de denúncia contra a violência contra a mulher.

A autora adotou a etnografia virtual e analisou em outubro de 2019 os coletivos feministas já indicados pela literatura revisada sobre os sites: Think Olga, Não Me Kahlo, Geledés, Blogueiras Negras, Escreva Lola Escreva, Blogueiras Feministas, Biscate Social Club, Gorda e Sapatão, Transfeminismos. Entre as preocupações dos diversos grupos está o combate à violência contra a mulher e a divulgação de casos de feminicídio como forma de conscientizar as seguidoras (WOIDA, 2020, p. 8).

A autora constatou que os grupos não são homogêneos. Há diversas perspectivas do feminismo, dependendo do problema enfrentado: racismo, lesbianismo, maternidade, transfobia, violência, corpo, sexualidade etc. O que deve interessar à ciência da informação é a constatação de que as tecnologias são aliadas ao processo de conscientização, mobilização e emancipação, mas 
podem ser consideradas uma barreira: "O movimento feminista se vale da tecnologia para difundir informações, mas também a têm como barreira, uma vez que a apropriação das tecnologias é reconhecida na literatura como menor entre as mulheres quando comparada aos homens [...]." (WOIDA, 2020, p. 20).

Em outras palavras, apesar dos benefícios das novas tecnologias, elas ainda representam uma barreira, pois a relação de homens e mulheres com as tecnologias é ainda desproporcional. Assim, as táticas de organização e mobilização do grupo sempre ficam limitadas às condições, qualidade de acesso e fluência tecnológica das usuárias. Woida (2020, p. 20) conclui que a ciência da informação, quando atua para promover o acesso e a apropriação da informação pelas mulheres, representa peça importante ao ciberfeminismo, o que contribui ao empoderamento feminino.

Embora não seja possível relacionar aqui mais trabalhos dessa última categoria, deve-se registar que dentro dos estudos de gestão do conhecimento, inteligência competitiva, os trabalhos que tratam da liderança feminina e das dificuldades que as mulheres gestoras encontram nos diversos ambientes informacionais para aceder a postos de trabalho, devem constar como estudos crítico que colocam a mulher como objeto central de reflexão.

Além disso, devem ser incluídos os estudos que demonstram as diferenças de tratamento entre homens e mulheres em ambientes de trabalho que desenvolvem ações de informação. Pode-se mencionar ainda o conjunto de trabalhos sobre o uso de tecnologias pelas mulheres, as condições de acesso à informação, as competências informacionais específicas, as barreiras culturais da mediação da informação com esse público, a análise dos algoritmos sexistas nos sistemas de recuperação da informação, entre outras abordagens que buscam compreender a mulher e seu contexto social como objeto de reflexão.

Nesses estudos, compreender a significação dos fenômenos é importante para limitar a ação dos significantes que reproduzem o status quo. Nesses, o objeto se sobrepõe à palavra, o fato ao relato. Esses estudos crítico-revisionistas devem ser incentivados também em outras frentes não examinadas aqui, pois, apesar das limitações, uma nova proposta à ciência da informação sairá justamente das ações tomadas a partir desses resultados. 
A crítica da linguagem, significante e significado, é um procedimento fundamental, mas limitado em um projeto epistemológico feminista. As práticas científicas não são automaticamente alteradas com a acusação dos problemas dos instrumentos de organização do conhecimento.

Deve-se ir um pouco mais além e tomar como objeto de crítica a estrutura da ciência, as instituições, as relações de poder, os métodos, as noções de objetividade etc. Essas questões podem aproximar-se de um projeto epistemológico feminista à ciência da informação.

Os estudos crítico-revisionistas possuem um procedimento indutivo, da escolha de um conjunto de termos e instrumentos que denotam preconcepções, poderá se chegar a uma generalização válida para os demais. Contudo, devese pensar em revisões com característica dedutiva, em que se adotam premissas gerais das epistemologias feministas sobre a ciência que, por extensão, podese aplicar à ciência da informação como um todo. Com isso, segue-se para algumas implicações das epistemologias feministas à ciência da informação.

\section{QUESTIONAMENTOS E IMPLICAÇÕES DAS EPISTEMOLOGIAS FEMINISTAS À CIÊNCIA DA INFORMAÇÃO}

Como visto, avançou-se nos últimos anos no que se refere ao entendimento das questões de gênero e como estas moldam o campo da ciência da informação, desde a sua configuração profissional até os instrumentos que utiliza. Não obstante, precisa-se entrever que implicações e questionamentos as posturas das epistemologias feministas impõem. Concorda-se com a conclusão de Santo $(2008$, p. 327$)$ que constatou que "Incluir a mulher como objeto de estudo da $\mathrm{Cl}$ vai além da publicação de artigos em periódicos científicos que concluem ser pequena a participação feminina na construção do saber do campo."

Nesse sentido, não se pode concluir reiterando a escassez de trabalhos, mas indicar como estas perspectivas podem nos ajudar a formar um novo entendimento e posição da ciência da informação frente a esse projeto de ciência renovada.

Para incorporar elementos das epistemologias feministas à ciência da 
informação passa-se aos seguintes implicações: a concepção de ciência da informação, a discussão de sua identidade, a incorporação da teoria de gênero, a integração dos esforços de renovação da linguagem, o questionamento do gênero nos métodos de pesquisa e a neutralidade das tecnologias da informação. Embora não pareçam, esses temas dependem de uma perspectiva epistemológica que deve ser considerada. Entre empirismo, ponto de vista feminista e feminismo pós-moderno na ciência, pode-se elencar mais pontos que implicam mudanças na ciência da informação, no entanto, para iniciar o debate, considera-se que tais frentes sejam suficientes.

A primeira questão trata da definição da ciência da informação. Esse campo tem sido objeto de debate nas últimas décadas desde que o termo foi cunhado nos anos 1960. Aceita-se sem reserva que a história da ciência da informação esteve marcada pela corrida armamentista levada a cabo durante a Guerra Fria entre Estados Unidos e antiga União das Repúblicas Socialistas Soviéticas. Pode-se dizer que foi um dos exemplos típicos de uma ciência nascida com finalidade de apoio a estrutura estatal administrativa e militar.

Assume-se, às vezes sem discussão, que a ciência da informação, assim como outras ciências, criadas a partir do exemplo do projeto Manhattan (19391946), respondem à necessidade do planejamento e da gestão da ciência. Ao contrário da classificação da ciência da informação como ciência pós-moderna, a sua história demonstra um compromisso patente com a especialização e a instrumentalização do conhecimento científico cuja inspiração encontra esteio nos projetos modernos.

Nesse sentido, a ciência da informação, apesar do carácter aparentemente "soft" ou de ciência "mole", cumpre uma ideologia e um projeto de ciência androcêntrica. Não há como pensar na ciência da informação fora da grande empresa chamada Big Science, uma verdadeira indústria instrumentalizadora do saber. As formas de pensar o sujeito da informação ainda estão submetidas a esta estrutura industrial. Não sem razão ainda não se desvencilhou das teorias do "produtor" e do "consumidor" da informação. A lógica economicista com que se dispõem os espaços às pessoas ávidas de informação mostra que este é o verdadeiro paradigma, isto é, um paradigma utilitarista- 
economicista, disseminado a outras ciências é o único que parece explicativo, a despeito de nuances fisicalistas, cognitivistas e pseudossociais que roubam a cena.

Para iniciar a separação e o afastamento desse lógica, a ciência da informação deve ser pensada dentro dos parâmetros levantados pelas epistemologias feministas. Isso significaria concretamente propor uma nova definição de ciência, uma ciência feminista da informação que seja ao mesmo tempo, restauradora de uma nova objetividade, mais plural, que incorpore elementos da crítica liberal, para o melhor funcionamento pragmático, e da crítica radical, para aprofundar a noção de seus objetos. Pois não há apenas um objeto, apesar da míope insistência e da busca de exclusividade e autoridade no sempre renovado interesse em ter a última palavra sobre a definição da informação.

A competição entre qual é a mais ampla ou a mais restrita definição de informação, ou se deve receber a exclusividade um de seus processos (mediação, representação, gestão etc.), é um sintoma de uma ciência com resquício do secular espírito machista em dominar a arena da ciência. A unidade e a tendência à unificação ainda presidem o debate.

Uma ciência da informação que pretenda sair da disputa da exclusividade do objeto unitário deverá reconhecer que seus interesses perpassam pelas ações, os sujeitos, os processos e potencialmente pelos resultados mais reificados destas (ferramentas, instrumentos etc.). Assim, a ciência da informação poderá até conceber que seus objetos a impulsionam a alterar o próprio nome em razão da adequação com o que é realmente estudado.

Além disso, essa ciência da informação reconfigurada, menos conflitiva e mais compreensiva, poderá reconhecer que está no patriarcado a principal instituição de regulação da produção da informação e da reprodução das condições de acesso às suas tecnologias na sociedade. Portanto, decorre daí os vieses, os preconceitos e a discriminação, não apenas em países pobres, mas internamente nas principais potências. Essas tensões da sociedade conflitiva decorrem da relação da cultura patriarcal com a natureza. A ciência da informação deve ocupar-se principalmente da explicação dos fluxos desiguais de informação na sociedade. 
A informação não poderá ser considerada nem mesmo didaticamente um ente isolado, ou elemento dominado da relação sujeito-objeto. Essa relação do sujeito impositiva do cognoscente foi ultrapassada por outras abordagens epistemológicas, tal como a semiótica, mas ainda persiste quando o assunto é a informação. A informação só é produzida sob um único viés simbólico-semiótico cuja divisão do mundo decorre dos papéis socialmente construídos, e aqui o gênero deve receber a máxima importância, assim como a interseccionalidade.

Essa constatação não significa a aceitação do relativismo ou uma postura pós-moderna, mas apenas o reconhecimento de que a objetividade é limitada, mas trabalhável e precisa ser conquistada constantemente. A objetividade é um convite ao diálogo, e não a interjeição dogmática. Assim, os pesquisadores da ciência da informação devem ser convidados a redefinir a área e superar o clima de competição, de busca do discurso autorizado, do domínio da informação, da tese do objeto único, e aterrissar nos fenômenos difusos e plurais que envolvem a informação. O reducionismo e o determinismo importados de outras ciências "duras" não estariam nesse projeto.

O segundo questionamento que deriva das epistemologias feministas, trata da identidade da ciência da informação. A definição discutida anteriormente já dá sinais do que precisa ser feito a respeito. Por um lado, a ciência da informação tem recebido contribuições que a aproximam das ciências "duras", como ciências naturais e matemática. Essa concepção costuma valorizar o ideal de objetividade, o método único, a identificação de leis, sem muitos questionamentos ou mesmo compromisso como as pessoas que, ao fim e ao cabo, devem autorizar cientistas a pensarem assim e a usarem, quando possível, os resultados desse conhecimento. Isso ocorre notadamente nas linhas de investigação mais próximas da matemática e das tecnologias da informação.

Por outro lado, a ciência da informação, cujos traços das ciências humanas e sociais são fortes, tem buscado rotular o determinismo tecnológico como inadequado para compreender as necessidades das pessoas. A área retoma uma narrativa romântica sobre os sujeitos que estavam em um mundo ideal antes do uso intenso das novas tecnologias. Nesse último caso, há uma ideologia paternalista sobre o sujeito que utiliza a informação e as novas 
tecnologias. Esse paternalismo é uma manifestação patriarcal que objetiva cuidar do outro que, neste caso, necessita atenção e de um guia para melhor o conduzir a vida.

A ciência da informação poderia entender melhor as suas características e se ver como um outro modelo de ciência social aplicada. Em outras palavras, a identidade da ciência da informação como ciência social não the dá o direito de abdicar-se da tarefa de responder às demandas sociais por melhores e mais justas condições de acesso à informação. Nesse caso, as tecnologias são e serão fundamentais nas próximas décadas que prometem uma maior integração tecnológica em outras esferas da vida. Para tanto, a ciência da informação deveria preocupar-se menos com o lugar que ocupa dentro de uma tabela de classificação da ciência, pois esta, como se sabe, é apenas um instrumento de gestão dos recursos da ciência e não explica muito sobre a essência de um campo.

Outro ponto que decorre das preocupações das epistemologias feministas e que seria importante à ciência da informação, seria dar maior atenção a teorias dos papéis sociais e da construção do gênero. Deve-se compreender que os papéis socialmente construídos são fundamentais para explicar as práticas de apropriação da informação na sociedade. A ciência da informação pode valer-se da premissa da construção sociocultural do gênero para reestruturar as formas como compartilha o conhecimento, em especial, nos espaços tradicionais de acesso à informação (bibliotecas etc.). ${ }^{3}$

\footnotetext{
${ }^{3}$ Somente para fornecer um registro isolado do interesse do assunto gênero pela ciência da informação, Bufrem e Nascimento (2012) buscaram entender a situação das pesquisas sobre o tema gênero em grupos de pesquisa do CNPq. As autoras buscaram complementar a análise, identificando apenas 8 grupos registrados no diretório, segundo a expressão de busca "gênero", com o filtro "área de ciência da informação". Apesar da região sul do Brasil constar como a regisão com mais pesquisas, segundo o levantamento, "[...] no DGP/CNPq, não há grupo registrado e situado nos estados que compõem a região. Isso pode ser reflexo do alto índice de autores transeuntes $(83,78 \%)$, que não se aprofundam no estudo da temática [...]". Em 7/7/2021, foi realizado o mesmo levantamento pelo termo "gênero" nos campos "nome do grupo", "nome das linhas de pesquisa" e "palavras-chave das linhas de pesquisa", utilizando também o filtro para a área da ciência da informação e o resultado foi de apenas 8 grupos registrados, a saber: 1) Alaye - laboratório de pesquisa em informação antirracista e sujeitos informacionais - UFG, 2) Biblioteca, Informação e Sociedade - UFCA, 3) Ciência, Tecnologia e Sociedade - UFSCAR, 4) GeMinas - UFPB, 5) Indicadores métricos para a ciência e tecnologia - UNIR, 6) Informação e Metrias em Ciência e Tecnologia - UFRJ, 7) Museologia, Patrimônio e Memória - UnB, 8) NÓMADAS - Informação, Memória, Documento - UFF.
} 
Os profissionais da informação, desde os que executam atividades internas até os que atendem o público em ser serviços de informação, não se distanciaram de uma concepção androcêntrica de conhecimento humano. A ideia de que o humano contempla todas as mulheres não é uma realidade, pois as unidades de informação continuam reproduzindo a mesma cultura livresca com os mesmos cânones.

Acredita-se não ser suficiente os profissionais se apresentarem como pessoas democráticos e abertas ao discurso dos movimentos afirmativos nesses ambientes, quando na verdade a ordem de fundo não sofre uma crítica radical. Nesses e em outros espaços, pensadoras, políticas e críticas são constantemente invisibilizadas. Contemplar a perspectiva de gênero nesses espaços não é apenas garantir condições igualitárias para que meninas e mulheres possam informar-se. Significa repensar a distribuição da informação de modo a permitir que todos e todas conheçam os pensamentos de outras mulheres e, com isso, tenham consciência de outras experiências do humano.

Um quarto questionamento decorrente das epistemologias feministas seria a integração dos esforços de modificação da linguagem sexista nos instrumentos de organização do conhecimento. Essa estratégia é a mais avançada na ciência da informação, pois já reúne diversas iniciativas e estudos. Contudo, considera-se que o trabalho está ocorrendo de forma isolada, pois criticam-se sistemas universais de organização do conhecimento (CDD, CDU, tesauros etc.) já repletos de preconceitos. Alguns grupos desenvolveram instrumentos específicos, como tesauros sobre o tema, a exemplo do Tesauro de Género (TESAURO..., 2021), da Red de Centros de Documentación y Bibliotecas de Mujeres, ou o Tesauro de Mujeres (MEDIAVILLA HERREROS; FOLLA FERNÁNDEZ, 2014), do Instituto Universitario de Estudios de Género da Universidad Carlos III de Madrid. Uma proposta epistemológica abrangente deve considerar os demais instrumentos, inclusive os universais, e receber uma revisão completa de acordo com uma nova concepção de ciência e valorização do saber.

Apesar das iniciativas, entende-se que a teoria feminista implica mudanças mais profundas no interior de outras estruturas que representam 0 
conhecimento. Nesse sentido, mulher não é apenas um tema, matéria ou assunto que merece uma descrição específica por não ser contemplada pelos sistemas tradicionais. A epistemologia feminista impõe uma renovação nos parâmetros de organização, o que supõe a criação de novos sistemas e tabelas que facilitam a organização da informação, mas representem ao mesmo tempo um ponto do vista ético, ou como Olson (2003, p. 739) comentou sobre a desconstrução dos sistemas: "A desconstrução transgressiva mantém-nos culturalmente honestos."

No entanto, é necessário avançar nos convênios entre profissionais para o desenvolvimento de novos sistemas sobre as distintas ciências e temas sob uma perspectiva feminista abrangente, e não mitigar o que não pode ser consertado. Essa seria a contribuição a contribuição da ciência da informação para atingir o objetivo de alcançar igualdade de gênero, dentro do plano de desenvolvimento sustentável, também chamado Agenda 2030.

Decorre da discussão sobre a linguagem a incorporação de objetos e perspectivas de estudo. Essa quinta reflexão trata da inclusão dos pressupostos do empirismo feminista que são mais pragmático. Seria necessário incluir entre as frentes de estudo os seguintes temas: análise dos periódicos científicos em ciência da informação no que tange a análise da distribuição igualitária de espaço para pesquisadoras e pesquisadores, rever as políticas editoriais e a composição do conselho e comitês editoriais que nem sempre são igualitários ${ }^{4}$, entre outros objetos de pesquisa.

Scheibinger (2001) assevera que quanto mais elevada a posição e o prestígio em uma carreira, em especial, na ciência, menos mulheres ali se encontrará. Contudo, no caso específico da ciência da informação no Brasil, em que a esmagadora maioria de pessoas que formam a área são mulheres, especialmente no campo profissional (XAVIER, 2020), esses dados mostrariam de maneira patente a estrutura sexista da ciência, tal como observou Muller e

\footnotetext{
${ }^{4}$ Veja o caso, por exemplo, do conselho editoral da revista Encontros Bibli que na data de 0605-2021, de 14 membros do conselho editorial, apenas 2 são mulheres. https://periodicos.ufsc.br/index.php/eb/about/editorialTeam. A Brajis, por exemplo, na mesma data, contava com 11 membros, sendo 3 mulheres. Disponível em: https://revistas.marilia.unesp.br/index.php/bjis/about/editorialTeam.
} 
Martins (2019) no campo ocupacional.

Deve-se avançar em outras análises sobre a distribuição dos espaços de poder na ciência da informação. Outros estudos nesse sentido poderiam tratar da distribuição de citações nos artigos e entender que estas representam um poder simbólico que se converte em poder econômico. O empirismo feminista, embora limitado do ponto de vista da crítica epistemológica, pode orientar uma ocupação dos espaços de poder na ciência. Isso não significa impor ou substituir uma visão de mundo por outra, mas garantir que outras experiências e olhares possam recepcionar novas pesquisas. Keller lança o seguinte convite:

Possivelmente, os cientistas mais abertos (ou as cabeças mais científicas) podiam e deviam juntar as suas forças à das feministas, tentando identificar a presença de distorções afectando quer feministas quer cientistas, mesmo se por razões diferentes, - a fim de tornar essas ciências mais rigorosas. (KELLER, 2005, p. 58).

A sexta implicação seria voltada aos métodos de pesquisa. É comum identificar na ciência da informação o gênero como variável demográfica, assim como idade, renda etc. Os estudos não têm relacionado as variáveis institucionais e estruturais que impedem que se chegue em condições iguais, tanto para o fazer científico quando para a gestão da própria ciência.

Uma análise dos métodos e do desenho das pesquisas pode contribuir para identificar a carência de variáveis socioculturais e de gênero que explicam mais apropriadamente a conexão entre estrutura institucional e acesso à informação. Será necessário um aprofundamento nas metodologias feministas, além de realizar pesquisas sobre gênero que representaria o resultado das práticas de revisão e crítica.

Impõe-se também como mais uma implicação na direção da incorporação das epistemologias feministas à ciência da informação, o debate sobre a pseudoneutralidade das tecnologias de informação. Esse ponto não é novo, pois diversos estudos têm explorado a questão da exclusão digital. Contudo, nesse caso, deve-se seguir adiante e perguntar sobre as interferências machistas, tanto dos algorítimos quanto das interfaces que mediatizam a busca de informação.

Nesse sentido, entende-se que a alfabetização informacional supõe que 
a apropriação e a assimilação de tecnologia é condicionada pelo gênero. Os comportamentos de informação também são generizados por nossa sociedade e isso impede que pessoas acessem o conhecimento de maneira igualitária. Meninas e meninos quando buscam informações costumam utilizar critérios distintos. O planejamento das interfaces de recuperação da informação, assim como fazem na elaboração de videogames, deve observar os vieses e como estes interferem no acesso à informação.

Schiebinger (2001, p. 57) forneceu um interessante exemplo de como as crianças respondem de maneira distinta o uso de softwares educativos. Esses softwares, assim como qualquer outra interface de recuperação, oferecem uma disposição de signos que pode ser mais atrativa para os meninos e mais enfadonha para as meninas. Isso provoca um gap no aprendizado, por exemplo, de matemática, o que terá consequências no futuro quando da escolha de uma carreira científica.

Não é objetivo aqui discutir o tema dos algoritmos, mas deve-se sublinhar as descobertas recentes sobre o comportamento racista e machista dos sistemas de busca e inteligência artificial no reconhecimento facial. Com o "admirável mundo novo" prometido pela tecnologia $5 \mathrm{G}$, as pesquisas feministas deverão ser direcionadas também a este universo para que não se reproduzam os mesmos preconceitos nesse "novo mundo". No primeiro "Congreso Internacional Tecnologías $1+D+i$ para la lgualdad: soluciones, perspectivas y retos"(INTERNATIONAL..., 2021), realizado em abril de 2021, os problemas relacionados aos algoritmos machistas, racistas e da inteligência artificial implicada, foram discutidos com profundidade.

Acredita-se que esses seriam alguns pontos de partida para produzir estudos críticos mais consistentes, ou seja, aqueles que mergulham nas abordagens epistemológicas feministas deixando em segundo plano, embora não menos importante, os estudos mais horizontais sobre o tema gênero na área.

\section{CONSIDERAÇÕES FINAIS}

Retomando as palavras de Schiebinger (2001) quando pergunta de 
maneira retórica se o feminismo mudou a ciência, a autora responde que o mais importante é que o feminismo mudou o conteúdo do próprio conhecimento humano. Objetivou-se nesse arrazoado levantar alguns pontos para pensar nas consequências das epistemologias feministas na ciência da informação.

Presume-se como evidente que se está no caminho correto, os trabalhos críticos têm manifestado diversos problemas sobre o uso da linguagem na reprodução dos preconceitos, mas sugere-se olhar para outros lugares da área em que se faz necessária a incorporação mais aprofundada de uma abordagem feminista. Áreas em que o pensamento patriarcal se esconde sob um verniz pluralista podem ser perigosas, na medida em que seguem acriticamente as mesmas diretrizes sobre o que é ciência e quem está autorizado a defini-la.

Defende-se expressamente a necessidade de uma política reformista na ciência da informação. Para tanto, faz-se necessária uma política da gestão da ciência que identifique as práticas sexistas de reprodução do status quo, que reorganize os comitês das revistas para garantir a pluralidade, que se estabeleçam planos de igualdade de gênero - da composição de bancas e tribunais até as premiações -, que eventos contemplem essa perspectiva quando da escolha das palestrantes, que os trabalhos acadêmicos deem visibilidade a pesquisas, tanto de homens quanto de mulheres pesquisadoras, entre outros grupos. Essas medidas simples, embora de ação política, não afetarão a qualidade das investigações e não tratarão os que ali estão estabelecidos como ocupantes sem mérito. Essa seria uma alegação que retoma os discursos patriarcais sobre a ciência.

Entende-se que o potencial das colegas pesquisadoras poderia conduzir a área de maneira mais adequada e promover o conhecimento de outras experiências da vida social que, ao fim e ao cabo, beneficiaria a todas e a todos. Uma área generizada, como é o caso da ciência da informação, está mais próxima da renovação preconizada pelo paradigma feminista, mas deve reconhecer esse ativo nos níveis mais elevados de progressão acadêmica.

\section{AGRADECIMENTO}

O presente trabalho foi realizado com apoio da Coordenação de 
Aperfeiçoamento de Pessoal de Nível Superior - Brasil (CAPES) - Código de Financiamento 001 (Processo: 88887.571329/2020-00).

\section{REFERÊNCIAS}

ALFAYA LAMAS, E. La asunción del género neutro en la teoría y práctica de la organización del conocimiento. In: PÉREZ PAIS, M. C.; GONZÁLEZ BONOME, M. A. (ed.). 20 años del Capítulo Español de ISKO: actas del X Congreso ISKO-España. Ferrol, La Coruña: Universidade da Coruña, Servicio de Publicaciones, 2011. p. 249-263.

BUFREM, L. S.; NASCIMENTO, B. S. do. A Questão do gênero na literatura em ciência da informação. Em Questão, Porto Alegre, v. 18, Edição Especial, p. 199-2014, dez. 2012.

FERREIRA, M. M. O profissional da informação no mundo do trabalho e as relações de gênero. Transinformação, Campinas, v. 15, n. 2, p. 189-201, maio/ago. 2003.

FIORAVANTI, D. C. B.; NASCIMENTO, F. A.; SABBAG, D. M. A. A contribuição da organização de conhecimento no procedimento de classificação e indexação e nos processos crime com perspectiva de gênero: interpelações acerca dos feminicídios no Estado de São Paulo - Brasil. In: TRAMULLAS, J.; GARRIDO-PICAZO, P.; MARCO-CUENCA, G. (ed.). Actas del IV Congreso ISKO España-Portugal 2019: XIV Congreso ISKO España. Zaragoza: Capítulo Ibérico, 2020. p. 485-492.

FOX, M. J.; OLSON, H. A. Feminist epistemologies and knowledge Organization. In: SMIRAGLIA, R. P.; LEE, Hur-Li (ed.). Cultural frames of knowledge. Würzburg, Germany: Ergon, 2012. p. 79-97.

HARDING, S. Ciencia y feminismo. San Sebatián de los Reyes: Ediciones Morata, 2016.

INTERNATIONAL Congress "R\&D\&I Technologies for Equality: Solutions, perspectives and challenges", 1., 2021. Home. Disponível em: https://eventos.uc3m.es/63471/detail/tecnologias-idi-para-la-igualdadsoluciones-perspectivas-y-retos.html. Acesso em: 15 dez. 2021.

KELLER, E. F. Feminismo e ciência. In: LEVY, T.; QUEIROZ, C. (org.). Ciência e género: quatro textos de quatro mulheres. Lisboa: Cadernos de Filosofia das Ciências - CFCUL, 2005. p. 55-79.

LIMA, F. R. A.; DIAS, K. C. O. Levantamento das produções sobre mulheres e relações de gênero nos artigos de periódicos em ciência da informação.

Múltiplos Olhares em Ciência da Informação, Belo Horizonte, v. 3, n. 2, 
2013. Disponível em: http://hdl.handle.net/20.500.11959/brapci/69350. Acesso em: 17 maio 2021.

MATOS, G. I.; OLIVEIRA, E. F. T. Feminismos e estudos de gênero: uma abordagem bibliométrica. In: ENCONTRO NACIONAL DE PESQUISA E PÓSGRADUAÇÃO EM CIÊNCIA DA INFORMAÇÃO (ENANCIB), 18., 2017, Marília. Anais [...]. Marília: UNESP, ABECIN, 2017. Disponível em: http://hdl.handle.net/20.500.11959/brapci/104522. Acesso em: 28 jun. 2021.

MEDIAVILLA HERREROS, M.; FOLLA FERNÁNDEZ, R. Tesauro de mujeres. Madrid: Biblioteca de Mujeres, Instituto Universitario de Estudios de Género de la Universidad Carlos III de Madrid, 2014.

MONDÉJAR MADINA, A.; MARÍN GARCÍA, T.; SANTOS SERRA, R. CDU: perspectivas de género y discriminación de minorías. In: GARCÍA MARCO, F. $\mathrm{J}$. (org.). Organización del conocimiento en sistemas de información y documentación: actas del III encuentro de ISKO-España. Zaragoza: Universidad de Zaragoza, 1997. p. 103-118.

MORÁN SUÁREZ, M. A. ; RODRÍGUEZ BRAVO, B. La imagen de la mujer en la Clasicación Decimal Universal (CDU). In: EXTREMEÑO PLACER, A. I.

(org.). La representación y organización del conocimiento: metodologías, modelos y aplicaciones: actas del V Congreso ISKO-España. Madrid:

Universidad de Alcalá, 2001. p. 1-12.

MULLER, L. K. P.; MARTINS, C. W. S. Uma profissão feminina, mas não feminista? representatividade de gênero na gestão dos conselhos regionais de biblioteconomia no Brasil. Revista Brasileira de Biblioteconomia e Documentação, v. 15, p. 92-111, 2019. Disponível em: http://hdl.handle.net/20.500.11959/brapci/127489. Acesso em: 28 jun. 2021.

OLSON, H. Transgressive deconstructions: feminist/postcolonial methodology for research in knowledge organization. In: TRAVIESO RODRÍGUEZ, C.; FRÍAS MONTOYA, J. A. (org.). Tendencias de investigación en organización del conocimiento: actas del VI Congreso del Capítulo Español de ISKO. Salamanca: Universidad de Salamanca, Ediciones Universidad de Salamanca, 2003.

PINHO, F. A.; MILANI, S. O. Ética em organização do conhecimento: categorização de termos fronteiriços em relação a gênero e sexualidade.

Logeion: filosofia da informação, Rio de Janeiro, v. 6, n. 2, p. 84-103, 2020. Disponível em: http://revista.ibict.br/fiinf/article/view/5121. Acesso em: 28 jun. 2021.

SANTO, P. E. Os estudos de gênero na Ciência da Informação. Em Questão, Porto Alegre, v. 14, n. 2, p. 317-332, jul./dez. 2008.

SCHIEBINGER, L. Has feminism changed science? Cambridge: Harvard University Press, 2001. 
SICILIANO, M.; SOUZA, C. da M. de; METH, C. de M. e S. Sobre o que falamos quando falamos em gênero na ciência da informação? Informação \& Informação, Londrina, v. 22, n. 2, p. 144-165, maio/ago. 2017.

TESAURO de género: Tesauro de la Red de Centros de Documentación y Bibliotecas de Mujeres. Sevilla: Red de Centros de Documentación y Bibliotecas de Mujeres, Centro de Documentación María Zambrano, 2021. Disponível em: http://www.juntadeandalucia.es/iam/catalogo/doc/web/tesauro_genero.pdf. Acesso em: 15 dez. 2021.

VASCONCELOS, M. C. N.; FARIAS, G. B. Autoria feminina em ciência e tecnologia: cenário sobre a produção científica na ciência da informação. Convergência em Ciência da Informação, Aracaju, v. 3 n. 2, n. 2, p. 5-21, 2020. Disponível em: https://brapci.inf.br/index.php/res/v/142266. Acesso em: 28 jun. 2021.

WOIDA, L. M. Coletivos ciberfeministas como fonte de informação. Encontros Bibli: revista eletrônica de biblioteconomia e ciência da informação, Florianópolis, v. 25, p. 01-24, 2020.

XAVIER, A. L. S. A presença do feminino na biblioteconomia brasileira: aspectos históricos. 2020. 142 f. Dissertação (Mestrado em Ciência da Informação) - Faculdade de Filosofia e Ciências, Universidade Estadual Paulista, Marília, 2020.

\title{
EPISTEMOLOGIES AND INFORMATION SCIENCE: STUDIES AND IMPLICATIONS
}

\begin{abstract}
Objective: This paper presents critical-revisionist and non-revisionist studies on gender and women in information science, but maintains that only revisionist studies would be advanced the debate to raise epistemological-feminist issues in our area. Methodology: It follows a selective bibliographic procedure, and lists works that illustrate various themes related to women in information science. Results: To incorporate elements of feminist epistemologies into information science we need to review the conception of information science and its identity, to include the gender theory, to integrate a new language, to discuss gender in research methods, and neutrality of information technologies. Empiricism, feminist point of view, and postmodern feminism in science must imply changes in information science. Conclusions: Critical works have pointed several problems about the use of language and reproduction of prejudices, but it is suggested to look at other action fronts in the area in which deeper incorporation of a feminist approach is necessary. Patriarchal thinking hides under a pluralistic veneer, but follows the same guidelines of standard science and who is authorized to define it.
\end{abstract}

Descriptors: Feminist Epistemologies. Information Science. Critical Studies. 


\title{
EPISTEMOLOGÍAS Y CIENCIA DE LA INFORMACIÓN: ESTUDIOS E IMPLICACIONES
}

\begin{abstract}
RESUMEN
Objetivo: Presentar estudios crítico-revisionistas y no revisionistas sobre el tema género y mujer en la ciencia de la información, pero se entiende que solamente los estudios revisionistas se han comprometidos con el avance del debate con el fin de plantear cuestiones epistemológico-feministas en el área. Metodología: Sigue un procedimiento bibliográfico selectivo, enumerando trabajos que ejemplifican diversos temas relacionados con las mujeres insertas en las ciencias de la información. Resultados: Para incorporar las epistemologías feministas a la ciencia de la información se debe revisar la concepción de la ciencia de la información, la discusión de su identidad, la incorporación de la teoría de género, la integración de los esfuerzos de renovación del lenguaje, además se debe revisar los métodos y la supuesta neutralidad de las tecnologías de la información. Reflexionar sobre el empirismo, el punto de vista feminista y el feminismo posmoderno en la ciencia puede contribuir con cambios en la ciencia de la información. Conclusiones: Los trabajos revisionistas han manifestado varios problemas en el uso del lenguaje y la reproducción de prejuicios, pero se sugiere mirar a otros frentes en el área en los que es necesaria una incorporación más profunda del enfoque feminista. El pensamiento patriarcal se esconde bajo una capa pluralista, pero sigue las mismas pautas de la ciencia estánder.
\end{abstract}

Descriptores: Epistemologías feministas. Ciencia de la Información. Estudios Estudios.

Recebido em: 31.08.2021

Aceito em: 31.08 .2021 